University of South Carolina

Scholar Commons

$10-2006$

\title{
Fabrication and Characterization of Poly(Propylene Fumarate) Scaffolds with Controlled Pore Structures Using 3-Dimensional Printing and Injection Molding
}

\author{
Kee-Won Lee \\ Shanfeng Wang \\ Lichun Lu \\ Esmaiel Jabbari \\ University of South Carolina - Columbia, jabbari@mailbox.sc.edu \\ Bradford L. Currier
}

See next page for additional authors

Follow this and additional works at: https://scholarcommons.sc.edu/eche_facpub

Part of the Chemical Engineering Commons

\footnotetext{
Publication Info

Published in Tissue Engineering Part A, Volume 12, Issue 10, 2006, pages 2801-2811.

(C) Tissue Engineering Part A 2006, Mary Ann Liebert.

Lee, K.W., Wang, S., Lu, L., Jabbari, E., Currier, B.L., \& Yaszemski, M.J. Fabrication and Characterization of Poly(propylene fumarate) Scaffods with Controlled Pore Structures Using 3-Dimensional Printing and Injecting Molding. Tissue Engineering, 12(10). 2801-28011.

http://dx.doi.org/10.1089/ten.2006.12.2801
}

This Article is brought to you by the Chemical Engineering, Department of at Scholar Commons. It has been accepted for inclusion in Faculty Publications by an authorized administrator of Scholar Commons. For more information, please contact digres@mailbox.sc.edu. 
Author(s)

Kee-Won Lee, Shanfeng Wang, Lichun Lu, Esmaiel Jabbari, Bradford L. Currier, and Michael J. Yaszemski 


\title{
Fabrication and Characterization of Poly(Propylene Fumarate) Scaffolds with Controlled Pore Structures Using 3-Dimensional Printing and Injection Molding
}

\author{
KEE-WON LEe, M.S., SHANFENG WANG, Ph.D., LICHUN LU, Ph.D., \\ ESMAIEL JABBARI, Ph.D., BRADFORD L. CURRIER, M.D., \\ and MICHAEL J. YASZEMSKI, M.D., Ph.D.
}

\begin{abstract}
Poly(propylene fumarate) (PPF) is an injectable, biodegradable polymer that has been used for fabricating preformed scaffolds in tissue engineering applications because of in situ crosslinking characteristics. Aiming for understanding the effects of pore structure parameters on bone tissue ingrowth, 3-dimensional (3D) PPF scaffolds with controlled pore architecture have been produced in this study from computer-aided design (CAD) models. We have created original scaffold models with 3 pore sizes $(300,600$, and $900 \mu \mathrm{m})$ and randomly closed $0 \%, 10 \%, 20 \%$, or $30 \%$ of total pores from the original models in 3 planes. PPF scaffolds were fabricated by a series steps involving 3D printing of support/build constructs, dissolving build materials, injecting PPF, and dissolving support materials. To investigate the effects of controlled pore size and interconnectivity on scaffolds, we compared the porosities between the models and PPF scaffolds fabricated thereby, examined pore morphologies in surface and cross-section using scanning electron microscopy, and measured permeability using the falling head conductivity test. The thermal properties of the resulting scaffolds as well as uncrosslinked PPF were determined by differential scanning calorimetry and thermogravimetric analysis. Average pore sizes and pore shapes of PPF scaffolds with 600- and 900- $\mu \mathrm{m}$ pores were similar to those of CAD models, but they depended on directions in those with 300- $\mu \mathrm{m}$ pores. Porosity and permeability of PPF scaffolds decreased as the number of closed pores in original models increased, particularly when the pore size was $300 \mu \mathrm{m}$ as the result of low porosity and pore occlusion. These results show that 3D printing and injection molding technique can be applied to crosslinkable polymers to fabricate 3D porous scaffolds with controlled pore structures, porosity, and permeability using their CAD models.
\end{abstract}

\section{INTRODUCTION}

$\mathbf{P}$ OlyMERIC BiOMATERIals With INJECTABILITy and biodegradability have been widely used in tissue engineering. Unlike polymers used for making preformed scaffolds, injectable polymers can be crosslinked in situ through chemical reaction or ultraviolet (UV) laser after injection to fill skeletal defects through minimally invasive surgery. ${ }^{1-4}$ Of these polymers, poly(propylene fumarate) (PPF) is one of the promising material for tissue engineering applications, especially bone regeneration. PPF is an unsaturated linear polyester that can be crosslinked through carbon double bonds along its backbone $e^{5,6}$ and degraded by simple hydrolysis of the ester bonds into nontoxic products of propylene glycol, poly(acrylic acid-co-fumaric acid), and fumaric acid. ${ }^{7}$ Previous studies have also shown that the

Tissue Engineering and Polymeric Biomaterials Laboratory, Departments of Orthopedic Surgery and Biomedical Engineering, Mayo Clinic College of Medicine, Rochester, Minnesota. 
addition of ceramic components, such as $\beta$-tricalcium phosphate, to PPF enhanced both mechanical strength and osteoconductive properties of the scaffold. ${ }^{8,9}$

To date, most PPF scaffolds have been fabricated from crosslinking in combination with the salt-leaching technique. ${ }^{10,11}$ This method can fabricate highly porous scaffolds with various pore characteristics by controlling the content and size of salt particles. However, there are limited applications for the scaffolds with a thin membrane, spatially nonuniform distribution of salt particles, and incapability of internal channel control. To overcome these limitations, a solid freeform fabrication (SFF) technique has been considered as an alternative method. Because SFF is a computerized fabrication technique that can use computer-aided design (CAD) data directly, ${ }^{12,13}$ it has been used for manufacturing other 3-dimensional (3D), polymer scaffolds with controlled microstructures. Recently, stereolithography has been successfully applied to make 3D PPF scaffolds for critical-sized defects by using both UV photocrosslinking and salt leaching, ${ }^{14,15}$ but controlling internal structures and assessing their effects on the scaffolds have not yet been studied. Another approach using the SFF technique is to fabricate temporarily negative molds and cast the scaffold by using biomaterial suspensions. ${ }^{16-18}$ Based on the original scaffold design, negative molds were removed after they were cast by biomaterials such as collagen, ${ }^{19}$ ceramics, ${ }^{20-23}$ polymers, ${ }^{24}$ or their composites. ${ }^{25}$ Several studies have demonstrated that this method was capable of fabricating scaffolds with controlled internal structures as well as external shapes. ${ }^{19,20,22,23,25,26}$ Most scaffolds using a temporary mold have been fabricated by sintering ceramic or freezing a dispersion of collagen cast into the mold, which required a relatively high or low temperature condition. Furthermore, 10-20\% shrinkage was found in the resulting scaffolds fabricated using those materials. Therefore, injectable polymers with high crosslinkability may be suitable for fabricating 3D scaffolds to reduce shrinkage in the final scaffolds.

The objective of this study is to fabricate 3D porous PPF scaffolds and demonstrate the feasibility of controlling internal pore structures of fabricating scaffolds from predesigned CAD models. We first designed original CAD scaffold models with 3 pore sizes and various pore interconnectivities by closing different pore fractions in the models. Based on those models, 3D negative molds were printed and PPF scaffolds fabricated via in situ crosslinking in the molds. To assess the effects of controlled internal pore structures on scaffolds, the comparison between CAD models and PPF scaffolds has been performed in terms of porosity, pore morphology, average pore size, and permeability. The comparison between porous scaffolds, PPF itself, and a solid sample of crosslinked PPF without any pores has also implemented by measuring their thermal properties from differential scanning calorimetry (DSC) and thermogravimetric analysis (TGA).

\section{MATERIALS AND METHODS}

\section{Poly(Propylene Fumarate) synthesis}

All reagents were purchased from Aldrich Chemicals (Milwaukee, WI) and used as received, unless otherwise indicated. PPF was synthesized as described previously. ${ }^{27,28}$ Briefly, diethyl fumarate, excess amount of 1,2-propylene glycol were polymerized together with hydroquinone (crosslinking inhibitor) and zinc chloride (catalyst) first at $100^{\circ} \mathrm{C}$ for $1 \mathrm{~h}$ and then $150^{\circ} \mathrm{C}$ for $7 \mathrm{~h}$ to obtain fumaric diester intermediate. The intermediate was transesterified to form PPF under vacuum at $150^{\circ} \mathrm{C}$ for another $7 \mathrm{~h}$. Gel permeation chromatography (GPC) was used to determine the molecular weights and polydispersity of PPF. The GPC was carried out with a Waters 717 Plus Autosampler GPC system (Waters, Milford, MA) connected to a model 515 HPLC pump and model 2410 refractive index detector. Monodisperse polystyrene (PS) standards (Polysciences, Warrington, PA) with number average molecular weights $\left(\mathrm{M}_{n}\right)$ of 474, 6,690, 18,600, and 38,000 g/mol were used to construct the calibration curve. The $\mathrm{M}_{n}$ and weight average molecular weights $\left(\mathrm{M}_{w}\right)$ of the synthesized PPF were 3,460 and $7,910 \mathrm{~g} / \mathrm{mol}$, respectively.

\section{Scaffold modeling in computer-aided design}

We used 3D CAD software, Solidworks (SolidWorks Corp., Concord, MA), to create original scaffold models. Unit cell geometry is an orthogonal cubic lattice structure with square pores, which have 3 different sizes (300, 600, and $900 \mu \mathrm{m}$ ) and a $300-\mu \mathrm{m}$ strut thickness. Using the Boolean operation, each pore of original scaffold models was fully interconnected to the adjacent pores spaced by a 600$\mu \mathrm{m}$ strut thickness. Dimensions of 3 original scaffold models are $1.08 \times 1.08 \times 1.08 \mathrm{~cm}$ (for 300 and $600 \mu \mathrm{m}$ ) and $1.05 \times$ $1.05 \times 1.05 \mathrm{~cm}$ (for $900 \mu \mathrm{m}$ ). To control pore interconnectivity, we first calculated total pores in original scaffold models. The total number of closed pores for each scaffold was determined from calculating $10 \%, 20 \%$, and $30 \%$ of the total pores in 3 original scaffold models. Then we defined 2 outer layers and several intermediate layers in original scaffold models from 3 planes to allocate the number of closed pores to each scaffold. Based on these calculations, the total number of closed pores per layer was determined by dividing $10 \%, 20 \%$, and $30 \%$ closed pores into total number of layers, which was allocated randomly within each layer and closed by extruding feature in 3 planes: plane $1(x-y$ plane), plane 2 ( $y-z$ plane $)$, and plane 3 ( $x-z$ plane $)$.

\section{Poly(Propylene Fumarate) scaffold fabrication}

All CAD models were converted to stereolithography (STL) files, and then 2-dimensional (2D) sliced data (PTM) files with a $0.076 \mathrm{~mm}$ of thickness using the ModelWorks software (Solidscape Corp., Merrimack, NH). The 3D 
phase-change ink jet printer, PatternMaster, was used to create 3D scaffolds for printing PTM files layer by layer with a build material (PS) and a support material (wax). After printing, PS was dissolved by immersing printed scaffolds into acetone for $30 \mathrm{~min}$ to obtain wax molds. Subsequently, the wax mold was put into a Teflon holder, and PPF polymerizing mixture was injected under $100 \mathrm{mmHg}$ vacuum. PPF was crosslinked by a free radical polymerization using benzoyl peroxide (BPO), dimethyl toluidine (DMT), 1-vinyl-2-pyrrolidinone (NVP), and methylene chloride as free radical initiator, accelerator, crosslinker, and diluent, respectively. A typical procedure for preparation of the PPF polymerizing mixture was as follows. Two and a half grams of PPF and $1.0 \mathrm{~g}$ of NVP were mixed in a glass vial at $37^{\circ} \mathrm{C}$. One hundred microliters of initiator solution ( $50 \mathrm{mg}$ of BPO in $250 \mu \mathrm{L}$ of NVP) and $40 \mu \mathrm{L}$ of accelerator solution $(20 \mu \mathrm{L}$ of DMT in $980 \mu \mathrm{L}$ of methylene chloride) were added and mixed. To facilitate crosslinking, scaffolds were put into the oven at $40^{\circ} \mathrm{C}$ for $1 \mathrm{~h}$. After crosslinking was completed, the scaffolds were detached from the Teflon holder and wax was dissolved in a cleaner solution (BIOACT VS-O, Petroferm Inc., Fernandina Beach, FL) at $40-60^{\circ} \mathrm{C}$ for $1 \mathrm{~h}$. Finally, the scaffolds were dried completely at ambient temperature. All the scaffolds were fabricated at the same time using the same batch of PPF.

\section{Scaffold characterization}

Porosity. In CAD models, porosity was determined from

$$
\left[1-V_{\text {solid }} / V_{\text {total }}\right] \times 100(\%)
$$

Where $V_{\text {solid }}$ is the solid volume and $V_{\text {total }}$ is the total volume of scaffold. To determine porosity of PPF scaffolds, mass and all dimensions (length, width, and height) of 5 scaffolds were measured. Porosity of PPF scaffolds was calculated by

$$
\left[1-\left(m_{\text {scaffold }} / v_{\text {scaffold }}\right) / \rho_{P P F}\right] \times 100(\%)
$$

where $v_{\text {scaffold }}$ is the total volume, $m_{\text {scaffold }}$ is the dry mass of PPF scaffold, and $\rho_{P P F}$ is the density of PPF $\left(\sim 1.3 \mathrm{~g} / \mathrm{cm}^{3}\right){ }^{28}$

SEM analysis. Cold-field emission scanning electron microscopy (S-4700, Hitachi Instruments Inc., Tokyo, Japan) was used to examine the pore morphology of PPF scaffolds in the surface and cross-section. For crosssectional images, scaffolds were cryosectioned in liquid nitrogen through their middle parts parallel to planes 1 and 2 . All the scaffolds were viewed at $3 \mathrm{kV}$ accelerating voltage and $9500 \mathrm{nA}$ emission current. Average pore sizes were calculated from SEM images by using the biomedical image analysis software, Analyze (BIR Mayo Clinic, Rochester, $\mathrm{MN})$.
Permeability. Permeability was determined using the falling head conductivity test based on the Darcy's law. ${ }^{29}$ For comparison, we fabricated the PS scaffolds by dissolving the supporting wax from the printed scaffolds. Scaffolds were mounted to a Teflon holder, which was connected to a burette vertically held on a steel stand. Before the test, we determined $V_{\max }$ (the maximum volume of the burette) and $V_{i}$ (burette volume at a certain time $t_{i}$ ), and measured $h_{\max }$ (the height of the burette's maximum volume), $h_{\text {drip }}$ (the height of the drip point), and $L_{b}$ (distance from $V_{\max }$ to $V_{i}$ in the burette). From these values, $\Delta h_{o}$ (the initial head loss at zero time) and $\Delta h_{i}$ (the differential head loss at a certain time) were calculated by

$$
\begin{aligned}
\Delta h_{o} & =h_{\max }-h_{\text {drip }} \\
\Delta h_{i} & =h_{\max }-\left[\left(V_{\max }-V_{i}\right) \times\left(L_{b} / V_{\max }\right)+h_{\text {drip }}\right] .
\end{aligned}
$$

Then we filled water into the burette until $V_{\max }$ as the end of the scaffold holder was closed, and measured the time when the water ran through the scaffold until $V_{i}$. Measurement was performed in planes 1 and 2. The hydraulic conductivity $(K)$ was calculated by

$$
K=\left(a L / A t_{i}\right) \ln \left(\Delta h_{o} / \Delta h_{i}\right),
$$

where $a$ is the area of burette, $A$ is the area of scaffold, and $L$ is the height of scaffold. Finally, the intrinsic permeability $(k)$ was determined by

$$
k=K \mu / \rho g,
$$

where $\mu$ is the viscosity of water at $20^{\circ} \mathrm{C}(=1.00 \mathrm{cP}), \rho$ is the density of water $\left(=1.00 \mathrm{~g} / \mathrm{cm}^{3}\right)$, and $g$ is the gravitational acceleration $\left(\sim 981 \mathrm{~cm} / \mathrm{s}^{2}\right)$.

Thermal analysis. Prior to thermal analysis, 2 PPF scaffolds $(600 \mu \mathrm{m})$ and a solid PPF crosslinked sample were extracted in THF for overnight on a Soxhlet extraction apparatus for separating sol and gel fractions. The gel fraction of the samples was calculated by weighing the samples before the extraction and those dried afterward. DSC was measured on a TA Instruments (New Castle, DE) Q1000 differential scanning calorimeter at a heating rate of $10^{\circ} \mathrm{C} / \mathrm{min}$ in nitrogen. Each sample was preheated from room temperature to $100^{\circ} \mathrm{C}$ and cooled to $-90^{\circ} \mathrm{C}$ at a cooling rate of $5^{\circ} \mathrm{C} / \mathrm{min}$. Then the DSC scan was recorded via heating from -90 to $100^{\circ} \mathrm{C}$. TGA was done using a TA Instruments Q500 thermal analyst. The TGA data were obtained in flowing nitrogen at a heating rate of $20^{\circ} \mathrm{C} / \mathrm{min}$.

\section{Statistical analysis}

All the measured values were averaged and then represented by mean values \pm standard deviation in 5 samples. 


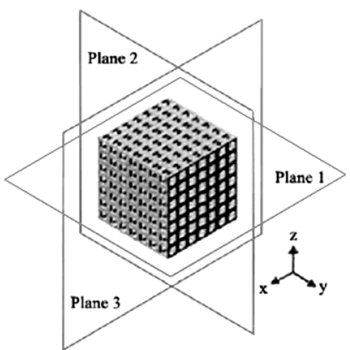

A

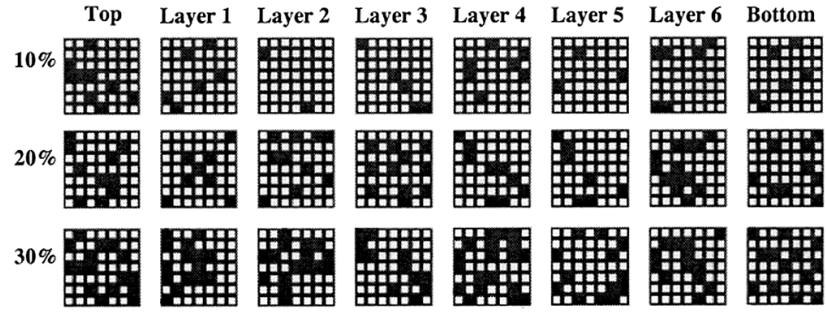

B

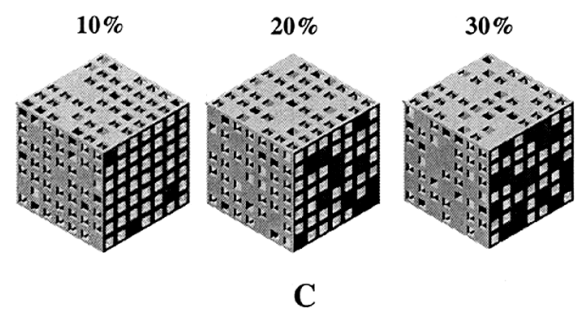

FIG. 1. Schematics of the original scaffold model and the pore interconnectivity control in CAD. (A) The original scaffold model with $900 \mu \mathrm{m}$ pores in 3 planes. (B) $2 \mathrm{D}$ sliced images (from top to bottom layer in plane 1) of the scaffold model with $10 \%$, $20 \%$, and $30 \%$ closed pores of total number of pores. (C) Final scaffold models.

Student's $t$-test was performed to assess statistically significances $(p<.05)$ of porosity and permeability between CAD models and PPF scaffolds.

\section{RESULTS}

\section{Computer-aided design model}

We generated 3D scaffold models with different pore sizes and percentages of closed pores in CAD (Fig. 1). Pore connection control was implemented by calculating total number of pores and different percentage closed pores in original scaffold models (Table 1) and closing them randomly in 3 planes. At a pore size of $900 \mu \mathrm{m}$, for example, scaffolds had 8 layers: 2 outer layers (top and bottom) and 6 intermediate layers. Each 2D sliced image represented randomly closed pores within 8 layers of scaffold in the plane 1. All dimensions (length $\times$ width $\times$ height) of PPF scaffolds no closed pores at 300-, 600-, and $900-\mu \mathrm{m}$ pore sizes were $(1.06 \pm 0.08) \times(1.07 \pm 0.05) \times(1.04 \pm 0.09) \mathrm{cm},(1.07 \pm$ $0.03) \times(1.07 \pm 0.03) \times(1.04 \pm 0.01) \mathrm{cm}$, and $(1.03 \pm 0.01) \times$ $(1.03 \pm 0.02) \times(1.02 \pm 0.04) \mathrm{cm}$, respectively. Comparing these data with those of CAD models, maximum percentage of decrease in each dimension of PPF scaffolds was only $1.9 \%$ for length and width, and $3.7 \%$ for height; however, there was no statistically significant difference between PPF scaffolds and CAD models.

\section{Poly(Propylene Fumarate) scaffold fabrication}

The fabrication process of PPF scaffolds consisted of 4 steps: (1) printing on a 3D phase-change ink jet printer, (2) dissolving the build material (PS), (3) injecting PPF, and (4) dissolving the support material (wax) (Fig 2). Printed scaffolds were composed of the green build material surrounded with the orange support material. Dissolving the build material was achieved by putting printed scaffolds into acetone. After dissolving build materials, negative wax molds for injecting PPF were obtained. Under the vacuum, PPF was infiltrated into pores of negative wax molds. Finally, PPF scaffolds were obtained by dissolving wax in a cleaner solution and drying them completely at ambient temperature. Like dissolving the build materials, completion of dissolving wax was indicated from the color change of the cleaner solution. This step consumes more time than the dissolving the build material, although it can be expedited at a higher temperature $\left(75^{\circ} \mathrm{C}\right)$.

\section{Porosity}

Based on pore connection control in CAD models, as the number of closed pores increased, porosity of both CAD

Table 1. Closed Pore Calculation of Three Original SCAFFolds IN COMPUTER-AIDEd DESIGN

\begin{tabular}{lrrr}
\hline Pore size $(\mu \mathrm{m})$ & 300 & 600 & 900 \\
\hline Number of pores in one row & 12 & 9 & 7 \\
Total number of pores in original models & 5616 & 2430 & 1176 \\
Total number of 10\% closed pores & 562 & 243 & 118 \\
Total number of 20\% closed pores & 1123 & 486 & 235 \\
Total number of 30\% closed pores & 1685 & 729 & 353 \\
\hline
\end{tabular}




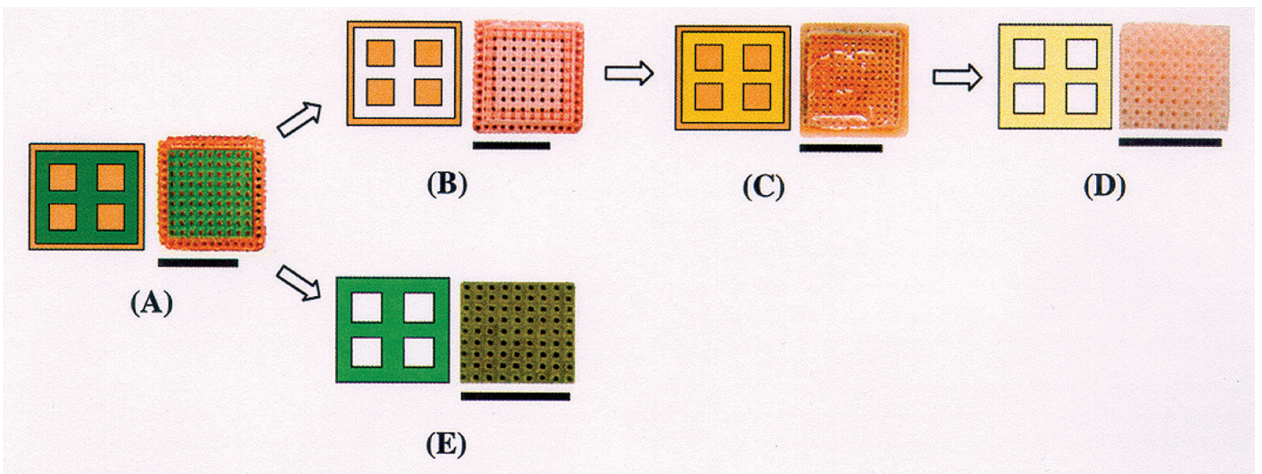

FIG. 2. The fabrication process of 3D PPF and PS scaffolds. (A) 3D printing (green: build material; orange: support material). (B) Dissolving build materials by using the acetone (white: pore). (C) Injecting the PPF (light yellow: PPF). (D) and (E) Dissolving support materials by using the cleaner solution (white: pore). Size bar $=1 \mathrm{~cm}$. Color images available online at www.liebertpub.com/ten.

models and PPF scaffolds decreased (Fig. 3). At a pore size of $300 \mu \mathrm{m}$, porosity of PPF scaffolds was significantly lower than that of CAD models in 4 different percentages of closed pores $(p<.05)$ and decreased abruptly to $29.5 \%$ in changing from 0 to $10 \%$ closed pore control. After this change, porosity decreased to $15.7 \%$ and $17.0 \%$ in 2 other closed pore controls. The difference of porosity between CAD models and PPF scaffolds increased as the number of closed pores from the original scaffold model increased (Table 2). However, there were no significant differences of
A

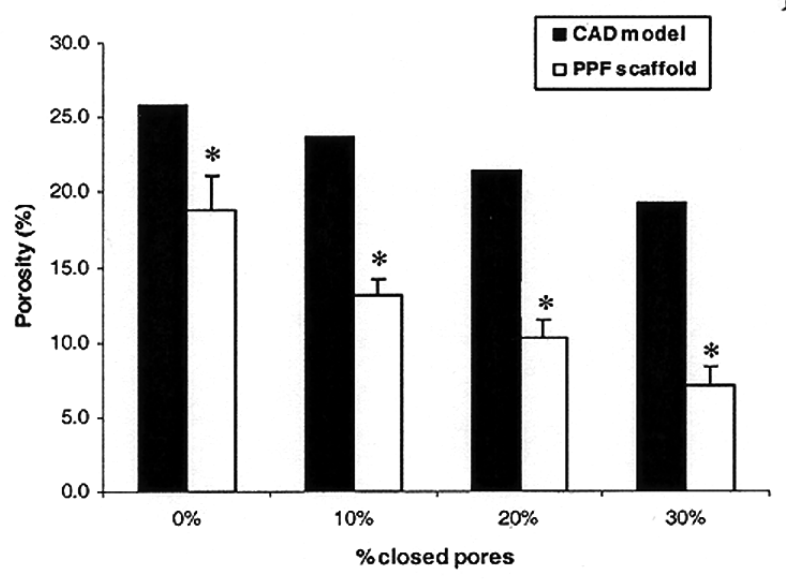

B

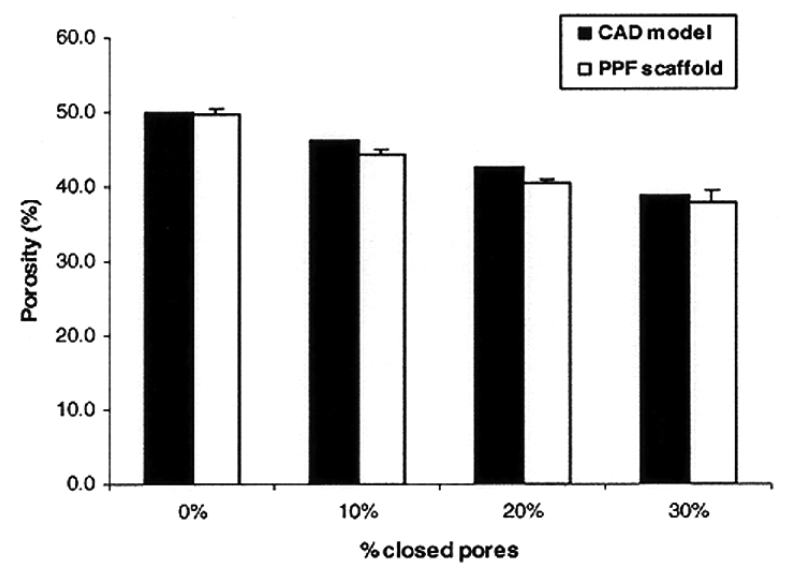

C

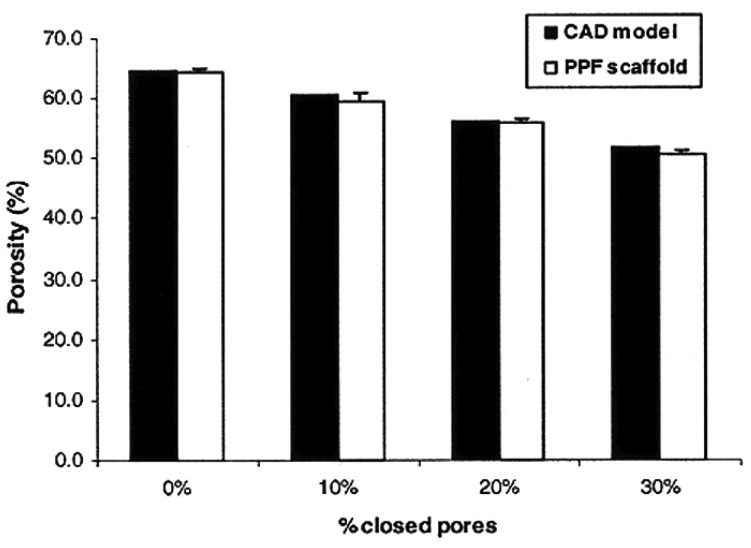

FIG. 3. Porosity of CAD models and PPF scaffolds: (A) $300 \mu \mathrm{m}$; (B) $600 \mu \mathrm{m}$; (C) $900 \mu \mathrm{m}$. *Statistically significant $(p<.05)$. Data depicted are from Table 2. CAD: computer-aided design; PPF: poly(propylene fumarate). 
porosity between CAD models and PPF scaffolds with 600 and $900 \mu \mathrm{m}$ pores. Similar to the pore size of $300 \mu \mathrm{m}$, the largest difference of porosity in PPF scaffold with $600 \mu \mathrm{m}$ pores occurred in the closed pore change from 0 to $10 \%$ closed pore control by $11.1 \%$. At the pore size of $900 \mu \mathrm{m}$, the largest difference of porosity occurred in the closed pore change from 20 to $30 \%$ closed pore control by $8.4 \%$ and in other 2 closed pore control porosity decreased to 7.6 and $5.3 \%$, which were close to CAD models.

\section{Scanning electron microscopic analysis}

Scanning electron microscopic (SEM) images have shown that pore shape was different from predefined planes and average pore sizes of PPF scaffolds were close to those of CAD models as pore size increased. In plane 1 , surface images of PPF scaffolds with $300 \mu \mathrm{m}$ pores revealed that pore shape was not consistent and some pores were occluded. Pore occlusion was widely observed in cross-sectional images and pore sizes decreased abruptly both in the surface $(239 \pm 31.5 \mu \mathrm{m})$ and cross-section $(88 \pm 24.2 \mu \mathrm{m})$ (Table 3). In plane 2, there were ruffled edges in both sides of the pore, and the printed layers were observed in all the SEM images. Average pore sizes of PPF scaffolds with $300 \mu \mathrm{m}$ pores in the surface and cross-section were larger than those in plane 1. On the other hand, PPF scaffolds with 600 and $900 \mu \mathrm{m}$ pores had consistent square pores similar to their CAD models; no occlusions were observed in either plane. No significant difference in average pore size was observed for the surfaces and the cross-sections of all PPF scaffolds.

\section{Permeability}

The permeability of PPF and PS scaffolds with 600 and $900 \mu \mathrm{m}$ pores was close to one another, but there was significant difference between the 2 scaffolds with $300 \mu \mathrm{m}$ pores (Fig. 5). At a pore size of $300 \mu \mathrm{m}$, permeability of PPF scaffolds in plane 1 was ranged from $2.19 \times 10^{-11}$ to $4.00 \times 10^{-14} \mathrm{~m}^{2}$ and significantly lower than that of PS scaffolds, whereas in plane 2 there was no significant difference in permeability between 2 scaffolds, except for the scaffolds with $10 \%$ closed pores. At pore sizes of 600 and $900 \mu \mathrm{m}$, the range of magnitudes was $1 \times 10^{-9} \mathrm{~m}^{2}$ and permeability in plane 2 was slightly higher than in plane 1; however, but there was no significant difference.

\section{Thermal properties}

The gel fractions of all 3 crosslinked PPF samples including 2 scaffolds with pore size of $600 \mu \mathrm{m}$ was close to $100 \%$, indicating all PPF chains have been crosslinked together. TGA has been performed to determine the weight loss of the dried samples when the temperature increases, as depicted in Fig. 6 for the 2 scaffolds, a solid crosslinked PPF sample, and PPF itself. One major degradation step could be found for all the samples at $325-350^{\circ} \mathrm{C}$; an additional small degradation step at $250^{\circ} \mathrm{C}$ could be observed in all the 3 samples made with crosslinked PPF. Consequently, the thermal stability of the crosslinked samples was slightly weaker than that of PPF, indicated by the different onset degradation temperatures $\left(\mathrm{T}_{d}\right)$ of $333^{\circ} \mathrm{C}$, $329^{\circ} \mathrm{C}, 327^{\circ} \mathrm{C}$, and $351^{\circ} \mathrm{C}$ for scaffold 1,2 , solid crosslinked sample, and PPF, respectively. A glass transition at $24.2^{\circ} \mathrm{C}$ for PPF as indicated in DSC in the inset of Fig. 6 could not be detected for the crosslinked samples as the result of diminishing free chain ends after crosslinking.

\section{DISCUSSION}

The 3D phase-change ink jet printer has been used for fabricating temporarily negative molds in indirect SFF techniques. ${ }^{19,23,25}$ This machine could precisely control the slice thickness using 2 thermoplastic materials. The lost mold technique we used was based on selective solubility of 2 materials in different solvents. This technique has been used $^{25}$ for producing wax molds because build materials were only dissolved in acetone. In this study, the use of a crosslinkable polymer PPF allows injection molding to fabricate scaffolds by in situ polymerization, which avoids high or low temperature processing for sintering ceramic or critical point drying. By comparing all dimensions of PPF scaffolds with no closed pores at 3 pore sizes to those of CAD models, we found that there was shrinkage of final scaffolds in the present fabrication technique, but the shrinkage was not significant owing to high crosslinking density and rigidity of the PPF network.

Pore sizes of original scaffold CAD models we designed were chosen as 3 macropores within greater than $300 \mu \mathrm{m}$. Because pore size of the scaffold directly affects porosity, transport of nutrients and metabolites, and tissue ingrowth, optimal pore sizes in tissue engineering applications has previously been investigated. Initial studies have indicated that the minimum requirement of pore size for scaffold is $100 \mu \mathrm{m}^{30}$ and the range of 300 to $400 \mu \mathrm{m}$ pore sizes is optimal in bone formation from comparing hydroxyapatite blocks with different pore sizes. ${ }^{31}$ Subsequent studies have also shown that macropore size within the range of 200 to $1,000 \mu \mathrm{m}$ diameters has a greater influence on bone ingrowth than macroporosity percentage. ${ }^{32}$ Pore size above $300 \mu \mathrm{m}$ has also been recommended for in vivo bone formation because it increases ingrowth of bone cells as well as blood vessels. ${ }^{33}$ Based on the previous literature, we chose 3 levels of macropore sizes as small $(300 \mu \mathrm{m})$, medium $(600 \mu \mathrm{m})$, and large $(900 \mu \mathrm{m})$ within the possibly applicable range for in vivo bone formation.

Like pore size, pore interconnectivity has been recognized as an important parameter affecting the properties and functions of the scaffolds because it is directly related to cell migration, vascularization, and mass 
Table 2. Porosity Comparison between CAD Models and PPF Scaffolds

\begin{tabular}{|c|c|c|c|c|c|}
\hline Pore size $(\mu \mathrm{m})$ & $\%$ closed pores & $\begin{array}{c}\text { Porosity (\%) } \\
\text { CAD model }\end{array}$ & PPF scaffold ${ }^{a}$ & $\begin{array}{c}\% \text { difference } \\
C A D \text { model }\end{array}$ & PPF scaffold \\
\hline \multirow[t]{4}{*}{300} & $0 \%$ & 25.9 & $18.8 \pm 2.3$ & - & - \\
\hline & $10 \%$ & 23.7 & $13.2 \pm 1.1$ & -8.5 & -29.5 \\
\hline & $20 \%$ & 21.5 & $10.3 \pm 1.2$ & -17.0 & -45.2 \\
\hline & $30 \%$ & 19.3 & $7.1 \pm 1.3$ & -25.5 & -62.2 \\
\hline \multirow[t]{4}{*}{600} & $0 \%$ & 50.0 & $49.7 \pm 0.8$ & - & - \\
\hline & $10 \%$ & 46.3 & $44.2 \pm 0.9$ & -7.4 & -11.1 \\
\hline & $20 \%$ & 42.6 & $40.5 \pm 0.4$ & -14.8 & -18.5 \\
\hline & $30 \%$ & 38.9 & $37.9 \pm 1.6$ & -22.2 & -23.7 \\
\hline \multirow[t]{4}{*}{900} & $0 \%$ & 64.8 & $64.3 \pm 0.6$ & - & - \\
\hline & $10 \%$ & 60.5 & $59.4 \pm 1.5$ & -6.6 & -7.6 \\
\hline & $20 \%$ & 56.2 & $56.0 \pm 0.5$ & -13.3 & -12.9 \\
\hline & $30 \%$ & 51.9 & $50.6 \pm 0.6$ & -19.9 & -21.3 \\
\hline
\end{tabular}

\footnotetext{
${ }^{\mathrm{a}}$ Data represent mean $\pm \mathrm{SD}(\mu \mathrm{m}) ; n=5$.

${ }^{\mathrm{b}} \%$ difference was calculated by [(porosity of different $\%$ closed pores - porosity of $0 \%$ closed pore) / porosity of $0 \%$ closed
} pore $] \times 100$.

transport $^{3,12,20,25}$; however, little work has been presented on fabricating scaffolds with controlled interconnectivity or subsequently assessing its effects. To quantitatively assessing the effects of pore interconnectivity on scaffold property, we designed CAD models with varied degrees of interconnectivity. Because increasing the number of closed pores in predefined layers of the CAD model decreases pore interconnectivity, we were able to control porosity and pore interconnectivity of scaffolds by varying the percentage of closed pores from total pores of CAD models. The scaffolds investigated in this study had either fully interconnected network with no closed pores or semiinterconnected network with $10 \%, 20 \%$, or $30 \%$ closed pores, which was similar to the typical scaffolds fabricated by various conventional techniques such as salt-leaching technique, which typically results in randomized pore connections inside the scaffolds, even at relatively high porosity.

As shown in Table 2, porosity of CAD models decreased constantly to $8.5 \%$ (for $300 \mu \mathrm{m}$ ), $7.4 \%(600 \mu \mathrm{m}$ ), and $6.6 \%$ $(900 \mu \mathrm{m})$ whenever the number of closed pores from original CAD models increased to $10 \%$. These decreased porosities were observed in PPF scaffolds, following decreased permeability of PPF scaffolds. But, porosity decrease of PPF scaffolds with $300 \mu \mathrm{m}$ pores did not match that of CAD models, owing to some possible reasons. First, original CAD model with $300 \mu \mathrm{m}$ pores had low porosity (25.9\%). Porosity of CAD models depended mainly on a pore size and a strut thickness, which were determined as $300 \mu \mathrm{m}$ in this study, considering a minimum printable feature size $(250 \mu \mathrm{m})$ of the machine. This strut thickness was $300 \mu \mathrm{m}$ between outer ends of each face and pores, but it was $600 \mu \mathrm{m}$ between 2 adjacent pores, which causes a low porosity in original CAD models with $300 \mu \mathrm{m}$ pores. Second, random pore closing led to reduced pore inter- connectivity within the scaffolds. Three original CAD models had only passing pores to connect 2 outer surfaces in each plane. However, as the number of closed pores increased, random closing in 3 planes increased nonpassing pores, which connect only 1 outer surface or isolated pores and have no connections to the adjacent pores or the outer surface in each plane. Although the apparent porosity we calculated could not distinguish passing pores from nonpassing or isolated pores, the effect of random pore closing was observed markedly in PPF scaffolds with $300 \mu \mathrm{m}$ pores. At this pore size, the largest difference of porosity between PPF scaffolds and CAD models was observed when the closed pore was changed from 0 to $10 \%$, and pore occlusions occurred in both the surface and the cross-section of PPF scaffolds, even without closed pores in plane 1 (Fig. 4). These results suggest that build and support materials might not be removed completely during the dissolving process.

The direction-dependent pore shape of fabricated scaffolds using the 3D phase-change ink jet printer has also been investigated by Wilson et al. ${ }^{23}$ Because 3D printing is a layer-based fabrication technique that can fabricate a 3D feature by printing its 2D slices with build and support materials and accumulating them subsequently in $z$ direction, pores of PPF scaffolds in plane 1 were generated directly by printing their 2D slices, but those in other planes were generated by an accumulating process. Basically, these 2 pore-generating processes have led to different pore shapes of PPF scaffolds in planes 1 and 2 (as shown in Fig. 4). From all the SEM images in the surface and crosssection, ruffled edges and printed layers in both sides of the pore were observed in plane 2. Also, while dissolving build materials, pores in plane 1 were only exposed and directly faced with the acetone. In the case of PPF scaffold with $300 \mu \mathrm{m}$ pores, acetone did not easily penetrate into deeper 
Surface

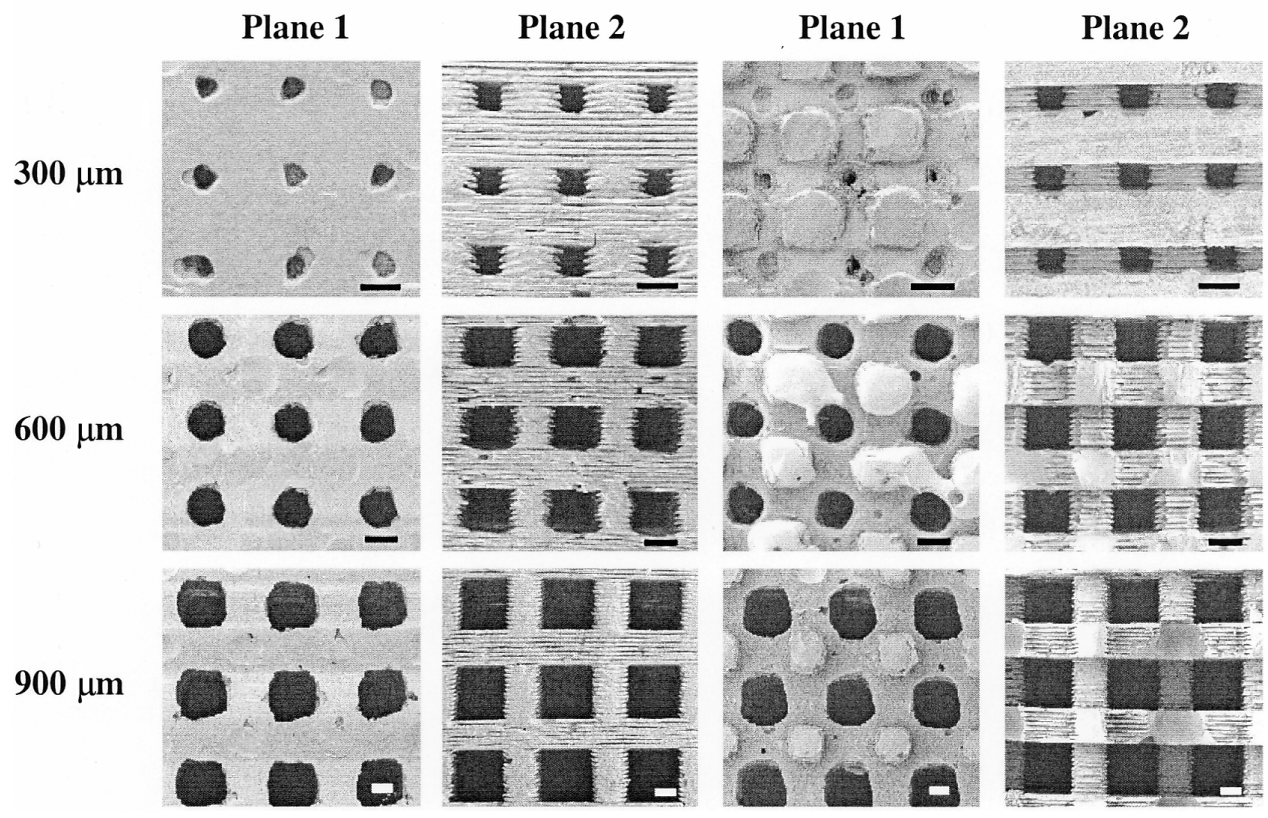

FIG. 4. SEM images of PPF scaffolds with $0 \%$ closed pores in 2 different planes. Size bar $=400 \mu \mathrm{m}$.

areas of the scaffold, which might influence changes of pore shape as round rather than square and reduced average pore sizes (as shown in Table 3). However, because pores in other planes were shielded by support materials and Teflon holders during PPF injection, pore shape was close to square and there were no significant differences of average pore sizes between PPF scaffolds and CAD models in the surface as well as cross-section, irrespective of pore sizes. Compared to the results from previous studies, average pore sizes of PPF scaffolds with $600 \mu \mathrm{m}$ pores in this study were similar to the original pore size of CAD models, but those with $300 \mu \mathrm{m}$ pores varied as different planes. Sachlos et al. ${ }^{19}$ fabricated collagen scaffolds with spheres and rods designed at different dimensions. The dimensions of the designed scaffolds with sphere of $600 \mu \mathrm{m}$ and interconnection of $300 \mu \mathrm{m}$ were approximately 590 610 and $340 \mu \mathrm{m}$, respectively. Wilson et al. ${ }^{23}$ fabricated hydroxyapatite scaffolds with square cross-sectional channels of $400 \mu \mathrm{m}$. The dimensions of channels were approximately 280 or $286 \mu \mathrm{m}$ in the $x-y$ plane, 376 or $394 \mu \mathrm{m}$ in the $y-z$ plane, and 339 or $352 \mu \mathrm{m}$ in the $x-z$ plane.
In addition to porosity and average pore size, permeability has been investigated in previous studies for describing structure of scaffolds and modeling of the porous materials. ${ }^{34-37}$ Because intrinsic permeability is a property of the porous scaffolds only, in contrast to the hydraulic conductivity, which is a property of both the porous scaffolds and the water content of the scaffold, it could be used an another parameter for characterizing the pore interconnection of PPF scaffolds in this study. Significantly low magnitude PPF scaffolds and large difference between PS and PPF scaffolds at a pore size of $300 \mu \mathrm{m}$ in plane 1 as compared to those in plane 2 (Fig. 5) have also mirrored effects of low porosity and random pore closing. Considered as a strong correlation between porosity and permeability when the pores of scaffolds are highly interconnected, ${ }^{38}$ the permeability we measured shows indirectly that the pores of PPF scaffolds are well interconnected.

Thermal analysis of the 2 porous PPF scaffolds (in Fig. 6) shows they are essentially the same as a solid crosslinked PPF sample and all are slightly weaker than uncrosslinked PPF in thermal stability because of the addition of

Table 3. Average Pore Sizes of PPf Scaffolds with 0\% Closed Pores in Two Different Planes

\begin{tabular}{llrrr}
\hline Pore size in CAD models $(\mu \mathrm{m})$ & \multicolumn{1}{c}{300} & 600 & 900 \\
\hline Plane 1 & Surface & $239 \pm 31.5$ & $617 \pm 16.7$ & $908 \pm 18.8$ \\
$(x-y$ plane $)$ & Cross-section & $88 \pm 24.2$ & $590 \pm 21.3$ & $912 \pm 19.8$ \\
Plane 2 & Surface & $271 \pm 20.6$ & $620 \pm 23.4$ & $917 \pm 13.8$ \\
$(y-z$ plane $)$ & Cross-section & $277 \pm 24.0$ & $598 \pm 21.2$ & $884 \pm 54.7$ \\
\hline
\end{tabular}

Data represent mean $\pm \mathrm{SD}(\mu \mathrm{m}) ; n=5$. 
Plane 1
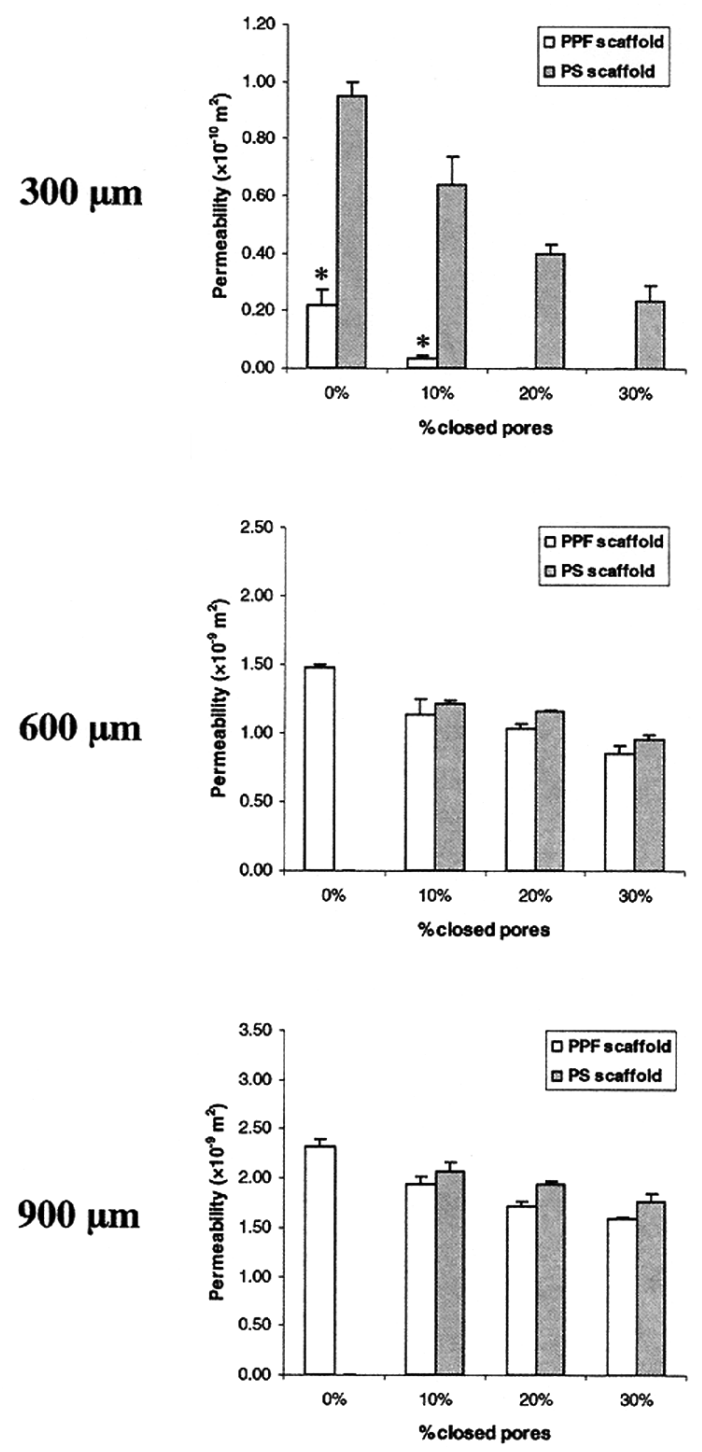

Plane 2
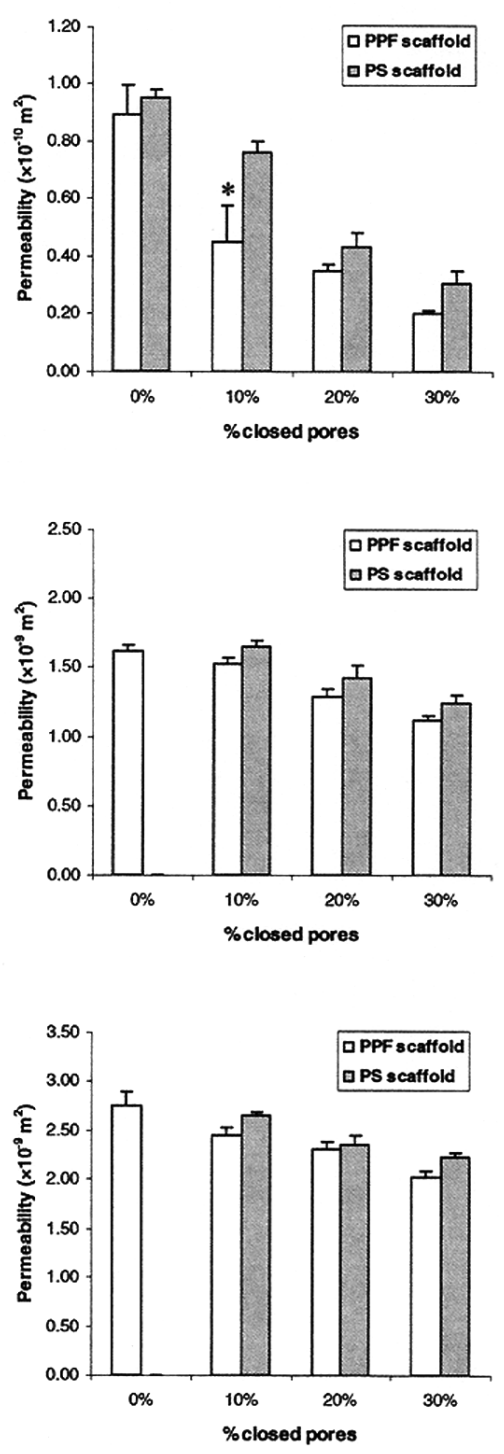

FIG. 5. Permeability of PPF and PS scaffolds in 2 different planes. *Statistically significant $(p<.05)$. There are no permeability data of PS scaffolds with $0 \%$ closed $600-$ and $900-\mu \mathrm{m}$ pores because they were broken. PPF: poly(propylene fumarate); PS: polystyrene.

crosslinker NVP in crosslinking. Nevertheless, crosslinked PPF samples in this study become rigid, strong, and solvent-resistant, and do not soften or flow at high temperature, whereas uncrosslinked PPF with an $\mathbf{M}_{w}$ of $7,910 \mathrm{~g} / \mathrm{mol}$ become a melt or even fluid when the temperature is higher than its glass transition temperature $\left(\mathrm{T}_{g}\right)$ of $24.2^{\circ} \mathrm{C}$.

In conclusion, 3D printing and injection molding technique was investigated to fabricate $3 \mathrm{D}$ porous polymer scaffolds with controlled pore structures. 3D phase-change ink jet printer was used to produce the 3D feature of scaffolds and temporarily negative molds for injection process. The use of injectable polymer PPF facilitated fabricating of scaffolds by in situ crosslinking. We also demonstrated that the internal pore structures of scaffolds can be directly controlled from their CAD models by changing pore sizes and closing different percentages the number of pores of original scaffold models in 3 planes. Our results show that control of pore size and connection of scaffolds in CAD affects porosity and permeability of resulting scaffolds, but fabrication of scaffolds with pore sizes of $300 \mu \mathrm{m}$ in plane 1 is still challenging because pore closing were implemented randomly in 3 planes. Thermal analysis also shows that scaffolds made by crosslinked PPF have a slightly weaker stability than uncrosslinked PPF while no glass transition was found for scaffolds. The further investigation in combination with specific pore allocation and the number of closed pores of scaffolds in 


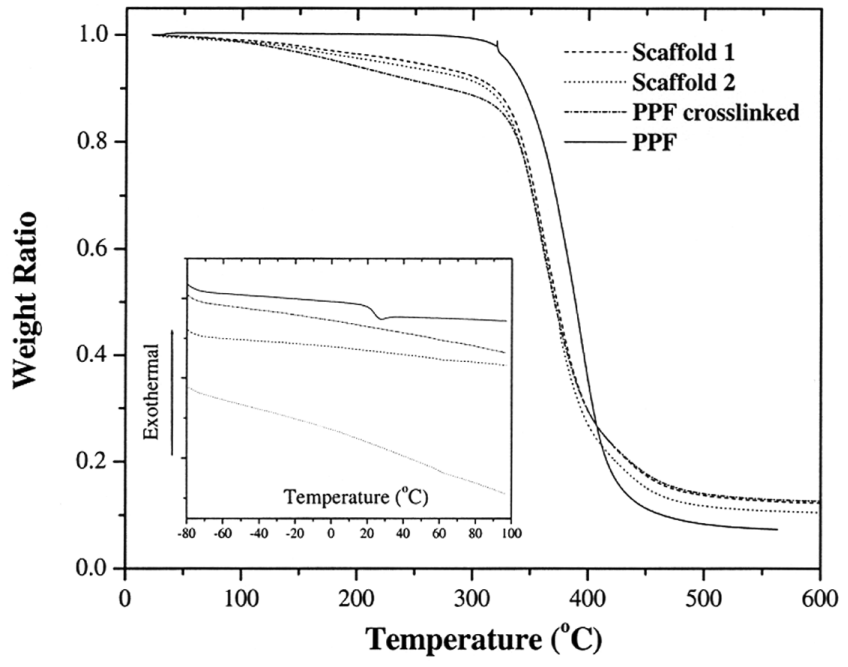

FIG. 6. TGA thermograms and DSC curves (inset) of the 2 scaffolds with pore size of $600 \mu \mathrm{m}$, a solid crosslinked PPF sample, and PPF itself. PPF: poly(propylene fumarate)

their CAD models will be expected to control internal pore structures, porosity, and permeability more accurately.

\section{ACKNOWLEDGMENTS}

This study was completed through funding provided by the Mayo Foundation and the National Institutes of Health (R01AR45871 and R01EB003060). The authors acknowledge James A. Gruetzmacher for technical assistance, Fredrick M. Schultz for manufacturing Teflon molds, and Jon E. Charlesworth for scanning samples with SEM.

\section{REFERENCES}

1. Temenoff, J.S., and Mikos, A.G. Injectable biodegradable materials for orthopedic tissue engineering. Biomaterials 21, 2405, 2000.

2. Agrawal, C.M., and Ray, R.B. Biodegradable polymeric scaffolds for musculoskeletal tissue engineering. J. Biomed. Mater. Res. 55, 141, 2001.

3. Lu, L., Zhu, X., Valenzuela, R.G., Currier, B.L., and Yaszemski, M.J. Biodegradable polymer scaffolds for cartilage tissue engineering. Clin. Orthop. 391, S251, 2001.

4. Peter, S.J., Yaszemski, M.J., Suggs, L.J., Payne, R.G., Langer, R.S., Hayes, W.C., Unroe, M.R., Alemany, L.B., Engel, P.S., and Mikos, A.G. Characterization of partially saturated ploy(propylene fumarate) for orthopedic application. J. Biomater. Sci. Polym. Ed. 8, 11, 893, 1997.

5. Peter, S.J., Miller, M.J., Yasko, A.W., Yaszemski, M.J., and Mikos, A.G. Polymer concepts in tissue engineering. J. Biomed. Mater. Res. 43, 422, 1998.

6. Domb, A.J., Manor, N., and Elmalak, O. Biodegradable bond cement compositions based on acrylate and epoxide termi- nated poly(propylene fumarate) oligomers and calcium salt compositions. Biomaterials 17, 411, 1996.

7. He, S., Timmer, M.D., Yaszemski, M.J., Yasko, A.W., Engel, P.S., and Mikos, A.G. Synthesis of biodegradable poly (propylene fumarate) networks with poly(propylene fumarate)diacylate macromers as crosslinking agents and characterization of their degradation products. Polymer, 42, 1251, 2001.

8. Peter, S.J., Kim, P., Yasko, A.W., Yaszemski, M.J., and Mikos, A.G. Crosslinking characteristics of an injectable poly (propylene fumarate) $/ \beta$-tricalcium phosphate paste and mechanical properties of the crosslinked composite for use as a biodegradable bone cement. J. Biomed. Mater. Res. 44, 314, 1999.

9. Peter, S.J., Lu, L., Kim, D.J., and Mikos, A.G. Marrow stromal osteoblast function on a poly(propylene fumarate)/ $\beta$-tricalcium phosphate biodegradable orthopedic composite. Biomaterials 21, 1207, 2000.

10. Yaszemski, M.J., Payne, R.G., Hayes, W.C., Langer, R.S., Aufdemorte, T.B., and Mikos, AG. The ingrowth of new bone tissue and initial mechanical properties of a degrading polymeric composite scaffold. Tissue Eng. 1, 41, 1995.

11. Fisher, J.P., Holland, T.A., Dean, D., Engel, P.S., Mikos, A.G. Synthesis and properties of photocrosslinked poly(propylene fumarate) scaffolds. J. Biomater. Sci. Polym. Ed. 12, 6, 673, 2001

12. Leong, K.F., Cheah, C.M., and Chua, C.K. Solid freeform fabrication of three-dimensional scaffolds for engineering replacement tissues and organs. Biomaterials 24, 2363, 2003.

13. Yang, S.F., Leong, K.F., Du, Z.H., and Chua, C.K. The design of scaffolds for use in tissue engineering. Part II. Rapid prototyping techniques. Tissue Eng. 8, 1, 2002.

14. Cooke, M.N., Fisher, J.P., Dean, D., Rimnac, C., and Mikos, A.G. Use of stereolithography to manufacture critical-sized 3D biodegradable scaffolds for bone ingrowth. J. Biomed. Mater. Res. Part B: Appl. Biomater. 64B, 65, 2002.

15. Fisher, J.P., Vehof, J.W.M., Dean, D., van der Waerden, J.P.C.M., Holland, T.A., Mikos, A.G., and Jansen, J.A. Soft and hard tissue response to photocrosslinked poly(propylene fumarate) scaffolds in a rabbit model. J. Biomed. Mater. Res. 59, 547, 2002.

16. Sun, W., and Lai, P. Recent development on computer aided tissue engineering-A review. Comput. Methods Programs Biomed. 67, 85, 2002.

17. Sachlos, E., and Czernuszka, J.T. Making tissue engineering scaffolds work. Review on the application of solid freeform fabrication technology to the production of tissue engineering scaffolds. European Cells Mater. 5, 29, 2003.

18. Hutmacher, D.W., Sittinger, M., and Risbud, M.V. Scaffoldbased tissue engineering: Rationale for computer-aided design and solid free-form fabrication systems. Trends Biotech. 22, 354, 2004.

19. Sachlos, E., Reis, N., Ainsley, C., Derby, B., and Czernuszka, J.T. Novel collagen scaffolds with predefined internal morphology made by solid freeform fabrication. Biomaterials $\mathbf{2 4}$, 1487, 2003.

20. Chu, T.M.G., Halloran, J.W., Hollister, S.J., and Feinberg, S.E. Hydroxyapatite implants with designed internal architecture. J. Mater. Sci. Mater. Med. 12, 471, 2001.

21. Bose, S., Darsell, J., Hosick, H., Yany, L., Sarrkar, D.K., and Bandyopahhyay, A. Processing and characterization of alumina scaffolds. J. Mater. Sci. Mater. Med. 13, 23, 2002. 
22. Hollister, S.J., Maddox, R.D., and Taboas, J.M. Optimal design and fabrication of scaffolds to mimic tissue properties and satisfy biological constraints. Biomaterials 23, 4095, 2002.

23. Wilson, C.E., de Bruijn, J.D., van Blitterswijk, C.A., Verbout, A.J., and Dhert, W.J.A. Design and fabrication of standardized hydroxyapatite scaffolds with a defined macroarchitecture by rapid prototyping for bone tissue engineering research. J. Biomed. Mater. Res. 68A, 123, 2004.

24. Sodian, R., Loebe, M., Hein, A., Martin, D.P., Hoerstrup, S.P., Potapov, E.V., Hausmann, H., Lueth, T., and Hetzer, R. Application for stereolithography for scaffold fabrication for tissue engineered heart valves. ASAIO 48, 12, 2002.

25. Taboas, J.M., Maddox, R.D., Krebsbach, P.H., and Hollister, S.J. Indirect solid freefrom fabrication of local and global porous, biomimetic and composite 3D polymer-ceramic scaffolds. Biomaterials 24, 181, 2003.

26. Chu, T.M.G., Orton, D.G., Hollister, S.J., Feinberg, S.E., and Halloran, J.W. Mechanical and in vivo performance of hydroxyapatite implants with controlled architecture. Biomaterials 23, 1283, 2002.

27. Kharas, G.B., Kamenetsky, M., Simantirakis, J., Beinlich, K.C., Rizzo, A.M.T., Caywood, G.A., and Watson, K., Synthesis and characterization of fumarate-based polyesters for use in bioresorbable bone cement composites. J. Appl. Polym. Sci. 66, 1123, 1997.

28. Wang, S., Lu, L., Gruetzmacher, J.A. Currier, B.L., and Yaszemski, M.J. A biodegradable and crosslinkable multiblock copolymer consisting of poly(propylene fumarate) and poly( $\varepsilon$-caprolactone): synthesis, characterization, and physical properties. Macromolecules 38, 7358, 2005.

29. Bowles, J.E. 12: Coefficient of permeability-Falling head method. In: Bowles, J.E., eds.. Engineering Properties of Soils and their Measurement, 4th ed. New York: McGraw-Hill Inc., 1992, pp. 121-128

30. Hulbert, S.F., Young, F.A., Mathews, R.S., Klawitter, J.J., Talbert, C.D., and Stelling, F.H. Potential of ceramic materials as permanently implantable skeletal prostheses. J. Biomed. Mater. Res. 4, 433, 1970.

31. Tsuruga, E., Takita, H., Itoh, H., Wakisaka, Y., and Kuboki, Y. Pore size of porous hydroxyapatite as the cell-substratum controls BMP-induced osteogenesis. J. Biochem. (Tokyo) 121, 317, 1997

32. Gauthier, O., Bouler, J.M., Aguado, E., Pilet, P., and Daculsi, G. Macroporous biphasic calcium phosphate ceramics: influence of macropore diameter and macroporosity percentage on bone ingrowth. Biomaterials 19, 133, 1998.

33. Karageorgiou, V., and Kaplan, D. Porosity of 3D biomaterial scaffolds and osteogenesis. Biomaterials 26, 5474, 2005.

34. Grimm, M.J., and Williams, J.L. Measurements of permeability in human calcaneal trabecular bone. J. Biomech. 30, 743, 1997.

35. Spain, T.L., Agrawal, C.M., and Athanasiou, K.A. New technique to extend the useful life of a biodegradable cartilage implant. Tissue Eng. 4, 343, 1998.

36. Kohles, S.S., Roberts, J.B., Upton, M.L., Wilson, C.G., Bonassar, L.J., and Schlichting, A.L. Direct perfusion measurements of cancellous bone anisotropic permeability. J. Biomech. 34, 1197, 2001.

37. Li, S.H., De Wijn, J.R., Li, J.P., Layrolle, P., and De Groot, K. Macroporous biphasic calcium phosphate scaffold with high permeability/porosity ratio. Tissue Eng. 9, 535, 2003.

38. Karande, T.S., Ong, J.L., and Agrawal, C.M. Diffusion in musculoskeletal tissue engineering scaffolds: Design issues related to porosity, permeability, architecture, and nutrient mixing. Ann. Biomed. Eng. 32, 1728, 2004.

Address reprint requests to: Michael J. Yaszemski, M.D., Ph.D.

Tissue Engineering \& Polymeric Biomaterials Laboratory

Department of Physiology and Biomedical Engineering

Department of Orthopedic Surgery Mayo Clinic College of Medicine

200 First Street SW

Rochester, MN 55905

E-mail: yaszemski.michael@mayo.edu 
